\title{
Closed-Loop Controller for Eliminating the Contact Bounce in DC Core Contactors
}

\author{
A. G. Espinosa, Member, IEEE, J. R. Riba, Member, IEEE, J. Cusidó, Member, IEEE, \\ J. A. Ortega, Member, IEEE, and L. Romeral, Member, IEEE
}

\begin{abstract}
The undesirable phenomenon of the contact bounce causes severe erosion of the contacts and, as a consequence, their electrical life and reliability are greatly reduced. On the other hand, the bounce of the armature can provoke re-opening of the contacts, even when they have already been closed. This paper deals with the elimination of the bounce in both contacts and armature of a commercial dc core contactor. This is achieved by means of a current closed-loop controller, which only uses as input the current and voltage of the contactor's magnetizing coil. The logic control has been implemented in a low cost microcontroller. Moreover, the board control can be fed by either dc or ac, and either in $50 \mathrm{~Hz}$ or $60 \mathrm{~Hz}$ so as to extend its applicability. A set of data is obtained from the measurement of the position and velocity of the movable parts for different operating voltages, and the dynamic behavior of the contactor is discussed.
\end{abstract}

Index Terms-Closed-loop control, contactors, contacts, fuzzy control.

\section{INTRODUCTION}

A T CLOSING contacts in an electromagnetic contactor, usually an arcing phenomenon occurs due to the bouncing of the moving contacts. The arcing energy can cause severe erosion of the contacts, particularly in the case of loads causing high inrush currents, like asynchronous motors starting, lighting applications, and so on. As a consequence, the electrical life and contact reliability are considerably shortened.

Contact make and break is a problem of concern to many researchers [1]-[6]. McBride et al. [1] have conducted deep and comprehensive analysis on electrical contact effects during the impact in the case of pivoting contacts. Two other related papers [5], [7] show that the first bounce time is longer for higher currents. Moreover, current loading considerably reduces subsequent bounces [5], [7]. In [8], the influence of the bonding area on contact erosion is studied, since bouncing behavior is an essential factor for contact erosion.

Manuscript received May 29, 2009; revised October 13, 2009. Date of publication June 21, 2010; date of current version October 1, 2010. This work received economic support from the Spanish Ministry of Science and Technology under the DPI 2004-03180 Research Project, as well as from General Electric Power Controls. Recommended for publication by Associate Editor T. J. Schoepf upon evaluation of reviewers' comments.

The authors are with the Motion and Industrial Control Group, Technical University of Catalonia, Terrassa 08222, Catalonia, Spain (e-mail: garciae@ee.upc.edu; jordi@euetii.upc.edu; jcusido@eel.upc.edu; jaortega@eel.upc.edu; romeral@eel.upc.edu).

Color versions of one or more of the figures in this paper are available online at http://ieeexplore.ieee.org.

Digital Object Identifier 10.1109/TCAPT.2010.2041456
The prevention of contact welding and new design concept contactors is shown in [9], [10]. Further investigations are being carried out to perform a new method in order to predict contact life in contactors [11].

New and improved models try to deal with the highly nonlinear dynamic behavior of the contactors [12]-[14]. Once an accurate model is obtained, the next step is to build up a control structure and many researchers have carried out different investigations in order to improve electromechanical contactor performance, employing electronic control. Davies et al. [15] published the first work presenting an implemented hardware.

Although controlled contactors are offered on the market, this is still a new relatively new design trend. The idea was to reduce the kinetic energy at impact time and was known as "kiss closing." The first ones were implemented by Westinghouse [16] and Fuji. In both cases, the magnetic circuit was conventional ac, with shading rings. The coil control occurred by changing the firing phase angle of a triac in series with the coil. Control was open loop and therefore the impact speed was affected by external factors, i.e., line voltage, and several internal parameters like spring constants, friction, mechanical parts, contact wear, mounting position, and so on.

The next step was to use a dc magnetic circuit and a coil. The main supply was initially full wave rectified and later the pulsewidth-modulation (PWM) technique was used [17], [18]. Voltage or preferably current control followed a preset reference profile, hence the control system had no position and speed feedback and thus only external disturbances were canceled.

A further step was to implement a closed-loop control of speed as a function of the moving armature position, in other words, the air-gap between both parts of the magnetic circuit. The first attempts used an external position measurement device, such as optical sensors [19], linear inductive, and others, but they have an unacceptable cost and a ruggedness too weak for attaching it to a contactor which expected endurance is several hundred thousands of operations or more. Furthermore, such sensors added a noticeable mass to the moving parts which in turn influenced the measures and the dynamical behavior.

Due to these drawbacks, investigators moved into indirect measurement systems. Most used magnetic flux as the control variable for calculating the position and speed of the moving 


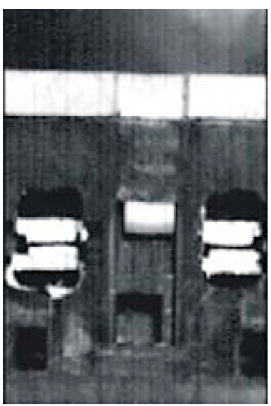

(a)

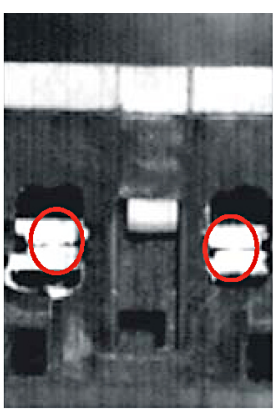

(b)

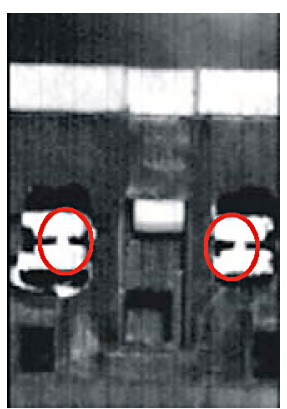

(c)
Fig. 1. (a) Moving contacts close to impact. Then (b) arcing begins at the first bounce and finally the (c) maximum arcing at the first bounce.

magnet. Usually, an auxiliary coil provides an electromotive force signal which integration leads to the flux value. Roschke and Bielau [20] improved the flux control accuracy using two sensor coils placed in an external leg of the double "E" cores. The second sensor coil and the main coil were placed in the central leg of the magnetic core. This layout allows one to take care of the leakage flux in the magnetic force calculation. Finally, Mitlmeier et al. [21] proposes to fix a permanent magnet to the moving armature in such a way that its movement induces an electromotive force or, better, a resistance change into a magnetic field sensor fixed to the static armature. In [22], a control unit was developed based on the variable-limit current control strategy and the closingdetection algorithm.

Fig. 1 shows the arcing phenomenon during contact closure and bouncing.

\section{CONCEPT DEVELOPMENT}

\section{A. Position Observer}

The magnetizing inductance of a U-shape contactor is related to the position of the moving armature [23]-[25] as follows:

$$
L=\frac{N^{2}}{\Re}=\frac{N^{2}}{\frac{1}{\mu_{0} \cdot S} \cdot\left[\frac{l_{T}}{\mu_{\mathrm{RHT}}}+2 \cdot x\right]}+K_{R} .
$$

Let $N$ be the number of turns of the coil, $\Re$ the reluctance of the magnetic circuit, $S$ the magnetic circuit cross-section, $\mu_{0}$ the permeability of air, $l_{T}$ the total length of the closed magnetic circuit, $\mu_{\mathrm{RHT}}$ the relative permeability of the closed system, $x$ the position of the armature, and $K_{R}$ a constant that takes into account the fringing flux.

From (1), (2) is obtained as follows:

$$
x=\frac{1}{2}\left(\frac{N^{2} \cdot \mu_{0} \cdot S}{L-K_{R}}-\frac{l_{T}}{\mu_{\mathrm{RHT}}}\right) .
$$

Thereby, (2) provides the position value, that is, the airgap value $(x)$ at each instant based only on the inductance and the current of the coil. The velocity can be obtained by differentiation at will

$$
v=\frac{x_{t}-x_{t-1}}{\Delta t} .
$$

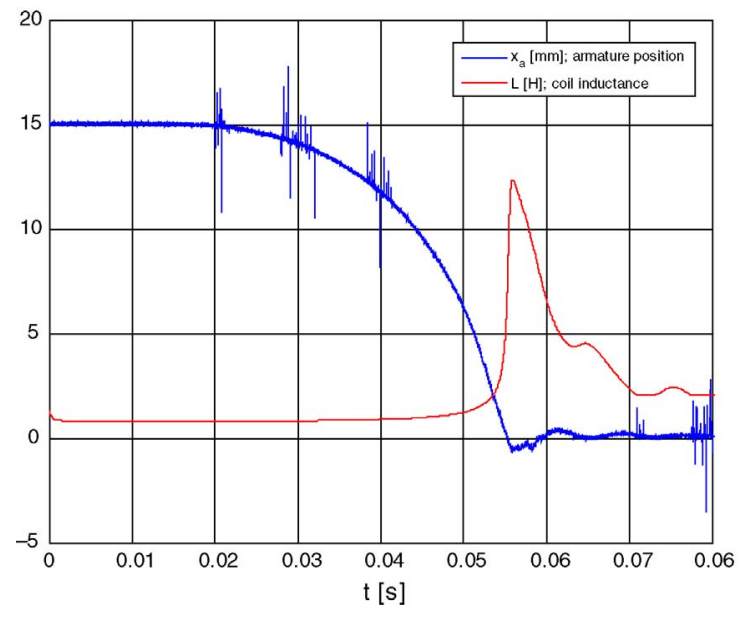

Fig. 2. Position and inductance profile during the closure.

Therefore, in order to calculate the position of the moving armature, it is mandatory to calculate the magnetizing inductance of the contactor. This is calculated by means only of the electrical variables available in the coil terminals of the contactor, it means the voltage $u$ and the current $i$. In this way, no additional sensor is used. Equation (4) describes the voltage in the coil due to the voltage drop caused by the resistance of the coil and the electromotive force, as a consequence of the motion of the moving armature

$$
u(t)=R i(t)+e m f(t)=R i(t)+N \cdot \frac{d \phi}{d t} .
$$

From (4) the linked flux can be obtained as follows:

$$
\phi=\frac{1}{N} \cdot \int_{0}^{t}(u-R \cdot i) \cdot d t .
$$

Taking into account that the inductance also can be expressed as

$$
L=N \frac{\phi}{i} \text {. }
$$

Equation (7) is obtained, wherein the magnetizing inductance is calculated from the measured voltage and current in the coil

$$
L=\frac{\int_{0}^{t}(u-R \cdot i) \cdot d t}{i} .
$$

However, in (7) the value of the resistance of the coil cannot be known since it varies according to the temperature of the place where the contactor is located as well as the type of duty of the contactor. For this reason at the beginning of each maneuver, this value must be calculated.

Fig. 2 displays the acquired profile of the armature position during closure and the inductance which has been computed according to (7).

\section{B. Calculation of the Initial Value of the Resistance and Inductance of the Coil}

The calculation of the initial resistance and the inductance is made at the beginning of each closing maneuver. It is carried 
out without any type of control of the current in order not to interfere with the shape of the current that is wanted to be sampled.

This circumstance of total conduction of the coil, that is duty cycle $\delta=1$, is extended during $20 \mathrm{~ms}$, or $11.1 \mathrm{~ms}$ after the closing order, depending on whether the contactor is ac or dc powered, respectively. If it is ac powered, the frequency of the network is calculated. It is carried out by means of zero crossing circuit detection, then the frequency is obtained by counting the time between two consecutive zero crossings.

The determination of the resistance as well as the inductance is made by (9)-(12). This procedure is based on the inductance at the beginning of the closure maneuver fulfill the next equation

$$
u(t)=R \cdot i(t)+\frac{d}{d t}(L \cdot i)=R \cdot i(t)+L \cdot \frac{d i}{d t}+\frac{d L}{d t} \cdot i .
$$

Note that while the circuit is being energized, the moving core is at rest. Equation (1) shows that under this restriction, the inductance is constant because the air gap $x$ is also constant, thus the last term of (8) can be neglected. Fig. 2 also corroborates this assumption.

\section{DC Powered Contactor}

$$
\begin{gathered}
R=\frac{E_{0}\left(\frac{\Delta i_{b}}{\Delta t_{b}}-\frac{\Delta i_{a}}{\Delta t_{a}}\right)}{i_{a} \cdot \frac{\Delta i_{b}}{\Delta t_{b}}-i_{b} \cdot \frac{\Delta i_{a}}{\Delta t_{a}}} \\
L=\frac{E_{0}\left(i_{b}-i_{a}\right)}{\frac{\Delta i_{a}}{\Delta t_{a}} \cdot i_{b}-\frac{\Delta i_{b}}{\Delta t_{b}} \cdot i_{a}} .
\end{gathered}
$$

\section{AC Powered Contactor}

$$
\begin{aligned}
& R=\frac{E_{\mathrm{peak}}\left(\sin \left(\omega \cdot t_{a}\right) \cdot \frac{\Delta i_{b}}{\Delta t_{b}}-\sin \left(\omega \cdot t_{b}\right) \cdot \frac{\Delta i_{a}}{\Delta t_{a}}\right)}{i_{a} \cdot \frac{\Delta i_{b}}{\Delta t_{b}}-i_{b} \cdot \frac{\Delta i_{a}}{\Delta t_{a}}} \\
& L=\frac{E_{\text {peak }}\left(\sin \left(\omega \cdot t_{a}\right) \cdot i_{b}-\sin \left(\omega \cdot t_{b}\right) \cdot i_{a}\right) \cdot \Delta t}{i_{b} \cdot \Delta i_{a}-i_{a} \cdot \Delta i_{b}}
\end{aligned}
$$

where $E_{0}$ is the value of dc voltage, $E_{\text {peak }}$ is the peak value of ac voltage, $\omega=2 \cdot \pi \cdot f$, wherein $f$ is the network frequency, $t(\mathrm{~ms})=2,2.5,3,5,5.5,6$

$$
\begin{aligned}
\bar{i}_{t} & =\frac{i_{(t-0.5)}+i_{(t-0.25)}+i_{(t)}+i_{(t+0.25)}+i_{(t+0.5)}}{5} \\
i_{a} & =\overline{i_{2.5 \mathrm{~ms}}} \\
i_{b} & =\overline{i_{5.5 \mathrm{~ms}}} \\
\Delta i_{a} & =\overline{i_{3 \mathrm{~ms}}}-\overline{i_{2 \mathrm{~ms}}} \\
\Delta t_{a} & =1 \mathrm{~ms} \\
\Delta i_{b} & =\overline{i_{6 \mathrm{~ms}}}-\overline{i_{5 \mathrm{~ms}}} \\
\Delta t_{b} & =1 \mathrm{~ms} .
\end{aligned}
$$

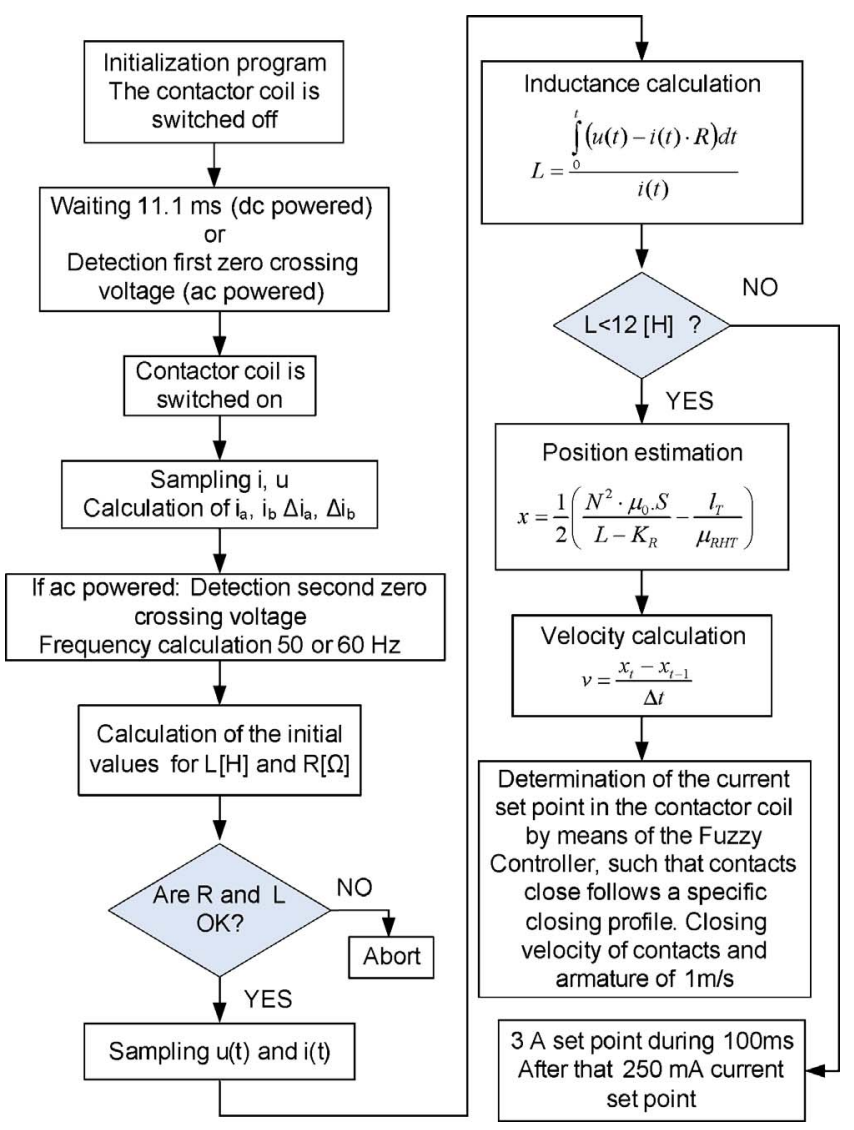

Fig. 3. Flow chart of the control system.

A flow chart of the overall control system is presented in Fig. 3 for better understanding of the control concept.

It should be pointed out that the closing velocity of both contacts and moving armature is set to $1 \mathrm{~m} / \mathrm{s}$, which assures no bounces in either the contacts or the armature. This value can change within limits depending on the characteristics of the contactor under study [26].

\section{CONTROL SCHEME}

Fig. 4 represents the diagram block of the presented closing control method. The control is implemented on two low-cost microcontrollers (PIC), model 16F876. The first PIC, called PIC 1, determines the current set point based on the calculated instantaneous coil inductance. The second PIC, called PIC 2, handles the closed-loop current control, in such a way that the computational load does not affect the control of the current. This structure allows the control to be faster than it would be if only implemented in one PIC.

Figs. 5 and 6 show the control software in case of dc and ac powered, respectively.

\section{A. PIC 1}

PIC 1 carries out the following calculations:

1) determination of ac or dc power conditions, frequency determination in case of ac powered;

2) coil inductance and resistance initial value determination; 


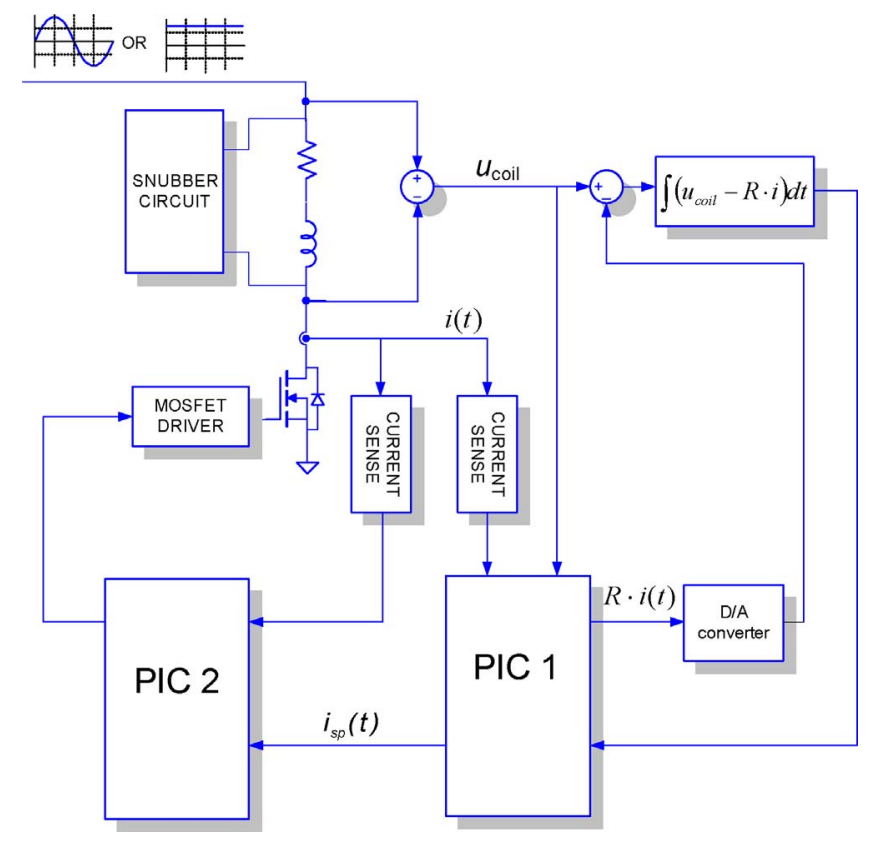

Fig. 4. Block diagram of the control system.

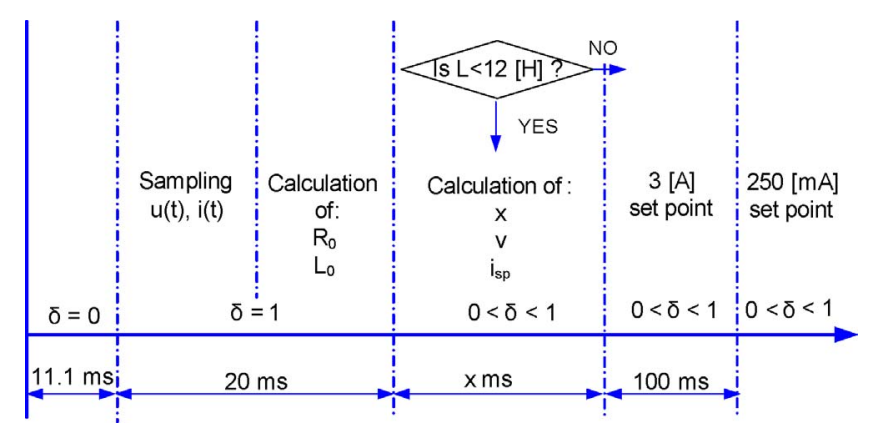

Fig. 5. Control software when contactor is fed by dc power.

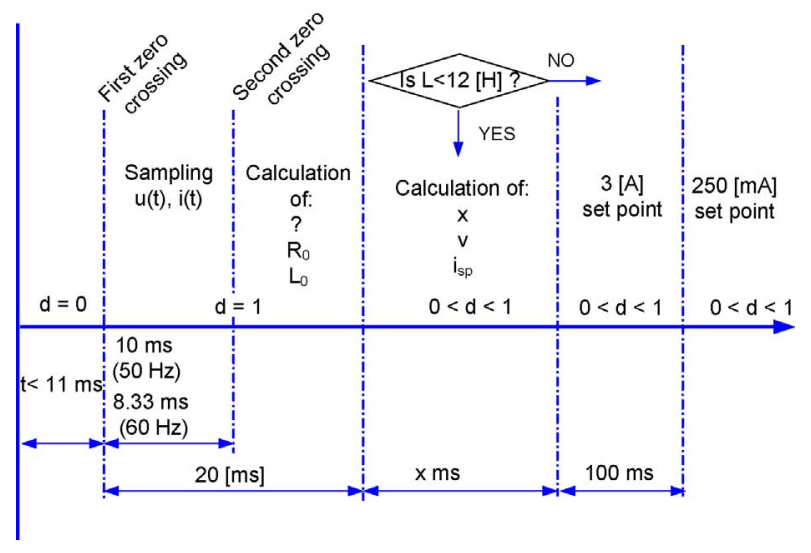

Fig. 6. Control software when contactor is fed by ac power.

3) on-line determination of the magnetizing inductance;

4) calculation of the instantaneous position and velocity of the armature in response to the calculated instantaneous coil inductance;

5) determination of the coil current set point in response to the instantaneous position and speed of the armature. In

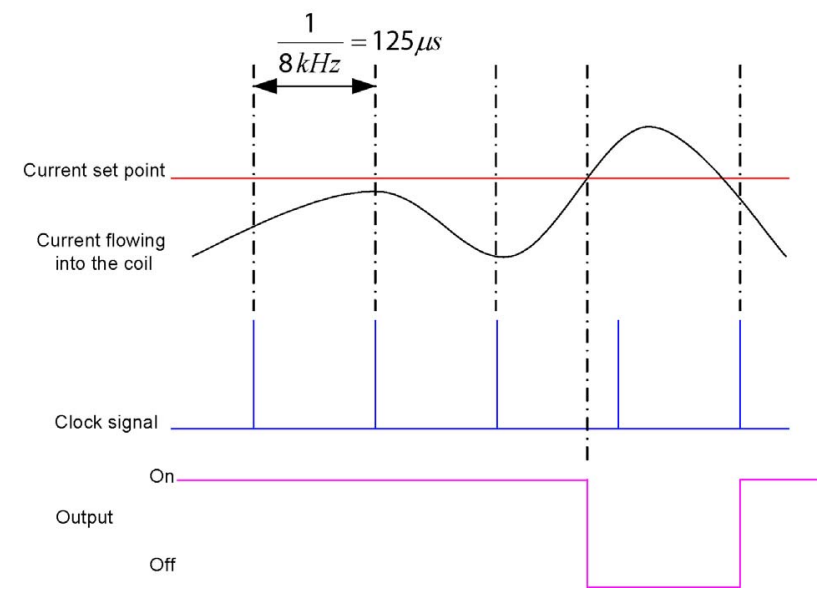

Fig. 7. Switch on and switch off patterns in the current closed loop.

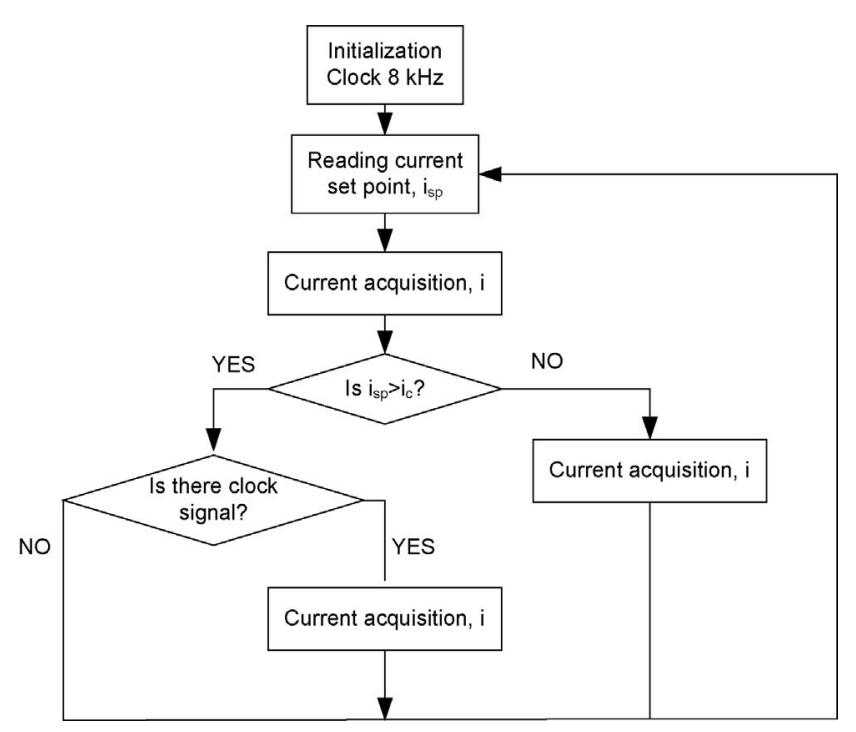

Fig. 8. Current closed-loop program.

this way, the instantaneous speed of the armature tends toward a target speed characteristic.

\section{B. $\quad$ PIC 2}

In the PIC 2, a closed-loop current control takes place. The PIC 1 calculates the set point current, which is compared with the actual current flowing through the coil. Thus, an error signal is generated. A PWM signal of $8 \mathrm{kHz}$ is generated in order to switch on or switch off the MOSFET. In Fig. 7, an example is shown to better explain how the current control works.

The flow chart of the current closed-loop program is shown in Fig. 8. It is worthwhile to note that this structure has been programmed in order to switch on the current in the precise instant that it is higher than the set point.

Then, the MOSFET is switched on again when there is a clock signal and the current is lower than the set point signal, thus avoiding an excessive amount of switching actions. When the armature is closed, the control scheme set $i_{\mathrm{SP}}=3 \mathrm{~A}$ during $100 \mathrm{~ms}$ in order to avoid re-breaking the contacts due to electromagnetic repulsion. The duty cycle is then implemented 


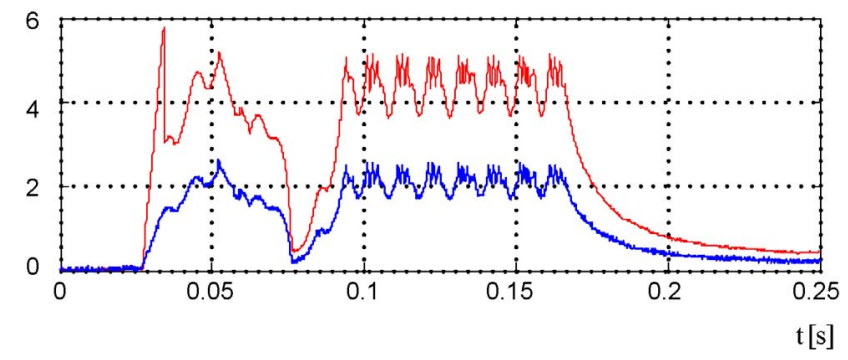

Fig. 9. Output of the Hall current sensor in blue color. Signal obtained with the variable gain to PIC 1 in red color.

such that it sets $i_{\mathrm{SP}}=250 \mathrm{~mA}$ to save energy and reduce the rise of coil temperature. This duty cycle provides enough current in the coil to keep the contactor closed in steady-state conditions.

\section{EleCtronic Module}

\section{A. Current Measurement}

The current of the coil is measured by means of a hall cell located just before the power transistor. This means the current can be measured in the transistor's two states; switch off or switch on. Thus, the noise produced by the transistor due to commutations will not affect measurements. The maximum output signal of the hall cell is $5 \mathrm{~V}$ which is also compatible with the A/D converters of the microcontrollers. However, at the beginning of the closure, the current is very low, $0.75 \mathrm{~A}$ or less. Thus, a variable gain amplifier is used, that is, during $10 \mathrm{~ms}$ after the closure order; the gain is 4 , decreasing to 2 at completion. Equation (13) displays the gain of the amplifier Q18 shown in Fig. 9

$$
G=1+\frac{R_{107}}{R_{106}+R_{110}+R_{129}+R_{126}} .
$$

When the transistor Q18 is switched on the gain is 2 , and when Q18 is switch off it is 4 .

The bottom line in Fig. 9 shows the output of the hall cell, whereas the upper line shows how the variable amplifier works. It is shown that until $10 \mathrm{~ms}$ the current is amplified four times. After this time the current is amplified twice that of its measured value. So, the full scale range of the converter is used in its entirety.

The circuit implemented is shown in Fig. 10. The same principle of operation is applied to PIC 2, as shown in Fig. 11. In this case the gain is 4 , as shown in (14), which is applied when the current is in holding state phase. It should be noted that the current level required for the making action and the current level in the holding state differs in one order of magnitude

$$
G=1+\frac{R_{119}}{R_{121}} .
$$

As already mentioned, in order to calculate the inductance, an electromotive force in the terminals of the coil is needed. The current through the coil is sampled at $4 \mathrm{kHz}$, and the product of $R \cdot i$ is performed into the microcontroller. This results in a digital output, which is converted into analogue by means

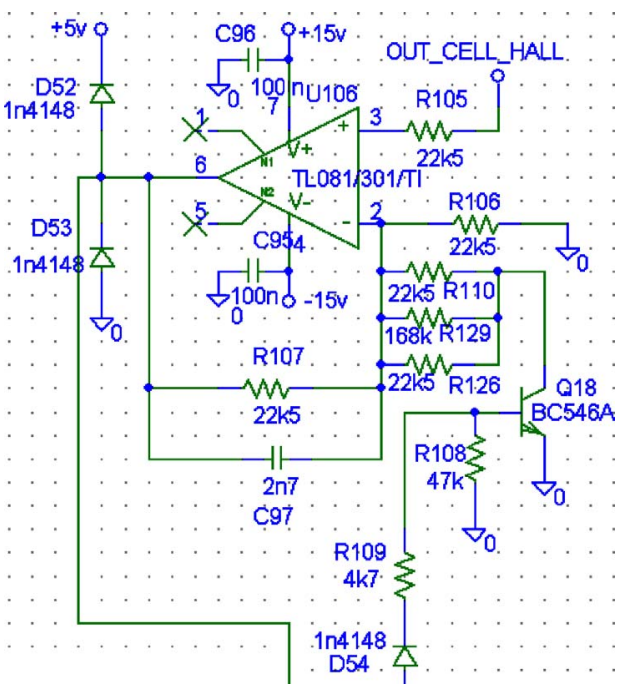

Fig. 10. Schematics of the variable amplifier PIC 1.

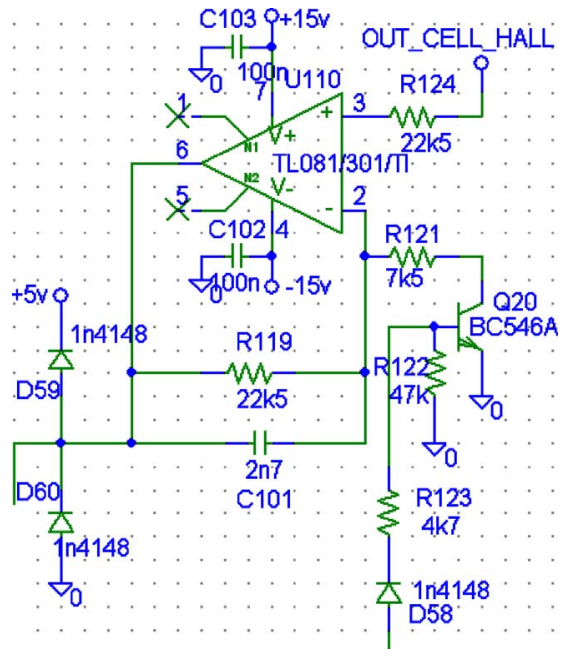

Fig. 11. Schematics of the variable amplifier PIC 2.

of a digital/analogical converter. Then, by subtracting from the voltage in the coil terminals, the voltage drop in the coil due to the resistance component results in an electromotive force in the coil. This is integrated, and flux is obtained. Equation (6) is then implemented into the microcontroller, resulting in the inductance of the coil in each instant. Afterward, the position and velocity are obtained by computing (2) and (3).

\section{B. Snubber Circuit}

This hardware, shown in Fig. 12, allows for current circulation in the coil when the Mosfet is switched off. It also offers a path for quick dissipation of the energy stored in the coil during the opening maneuver of the contactor. The quicker the energy of the coil is dissipated the faster the contactor will open, meaning the duration of the arc will be minimal. This is a very important feature since it allows for an improvement in the contactor's electrical endurance.

The circuit operates as follows. The idea is to make the energy of the coil in the Darlington transistor TIP 142 disappear, (Q16) taking into account that it operates in the linear zone of its characteristic $\mathrm{u}-\mathrm{i}$. 


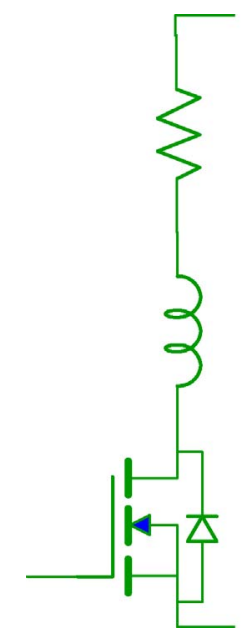

TIP142

Fig. 12. Schematics of recirculation circuit.

When the Mosfet is switched off long enough, the capacitor C84 is discharged thoroughly, previously loaded through the diode D48. The resistances R84 and R83 act as a current limiter during the charge process. When the Mosfet is driving, the C84 capacitor maintains Q16 in saturation.

When the Mosfet is switched off for a duration long enough to allow a discharge C84, Q16 begins to drive inside its linear zone. Under these conditions, there are $82-\mathrm{V}$ applied between collector and emitter (this value corresponds to the inverse voltage of the zener diode D47). This allows for a large amount of energy stored in the coil to dissipate.

\section{Current Control}

\section{A. Fuzzy Control of the Contactor}

During the life of the contactor, there are many variables involved in its dynamics that are alterable.

These are: voltage supply, room temperature, mechanical wear, tolerances/fatigue of the springs, contact wear, and changes of the initial air-gap. So, a conventional control based on PI controllers is not a suitable solution because its parameters should be continually adjusted.

In this paper, fuzzy control of the current through the contactor coil is used. Fuzzy control is suitable in cases when decisions must be made based on variables whose values present a certain degree of variability or uncertainty. One approach to the control of contactor bounce using fuzzy control provides, as output, a voltage which controls the closing rate of the contacts. This is an indirect control of the closing of the contactor since the attractive magnetic force is caused by the current in the coil [27].

In the work presented here, the inputs are the position and speed of the armature and the output is the current set point in the contactor coil. That is, the current that needs to flow through the coil at each instant is calculated based on the instantaneous value of the position and speed of the armature. Since these two variables are calculated, instead of being measured directly, their values may have a certain degree of uncertainty. Furthermore, the mechanical constants of the

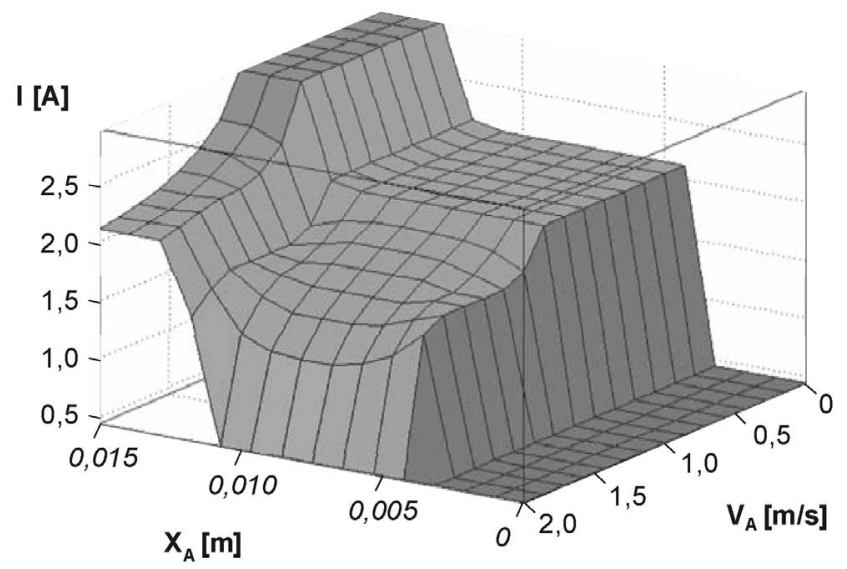

Fig. 13. 3-D graph of rules used in the adopted fuzzy system.

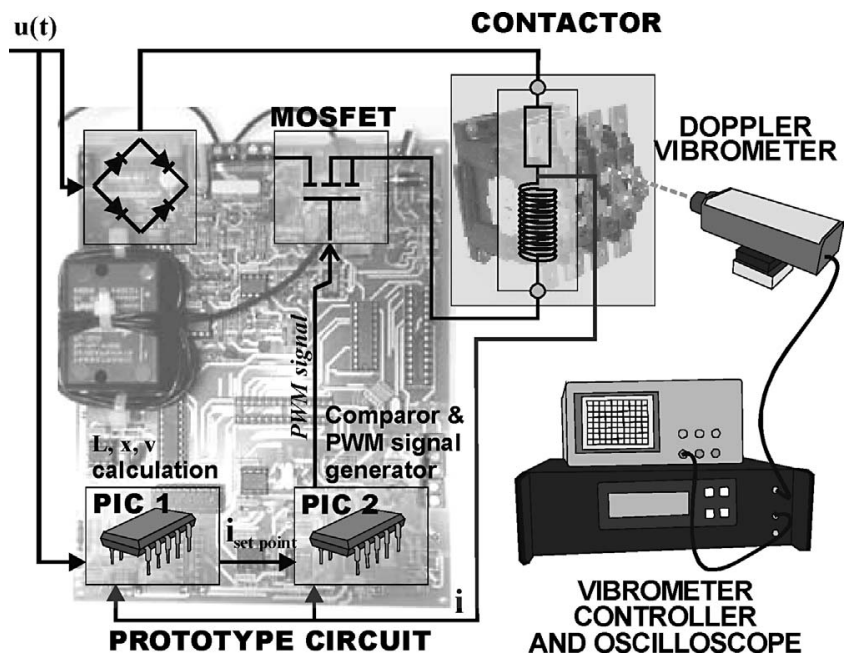

Fig. 14. Experimental setup.

contactor and the path of the armature may vary according to the wear of the components, such as spring constants, coefficients of friction, wear of mechanical parts, contacts, and so on. Hence fuzzy control is used.

The output of the new controller is the current set point, which is compared with the actual current. Thus, an error signal is generated. When the error is positive, the contactor coil is fed at the voltage supply, and when the error is negative, the coil is short-circuited. A PWM control in the contactor is thus implemented.

The two input variables are $x$ and $v$, the position and armature speed, respectively, and the output variable I, the set point current for the contactor coil. Fig. 13 depicts the 3-D map showing the output current for each set of input values.

Once the armature reaches the new contact position, the impact speed remains practically constant even if the contacts are worn down. Once the magnetic circuit is closed, that is, when the armature reaches the fixed magnetic core, full tension is applied to the contactor coil during $100 \mathrm{~ms}$ to avoid the rebreaking of the contacts due to the electromagnetic repulsion 


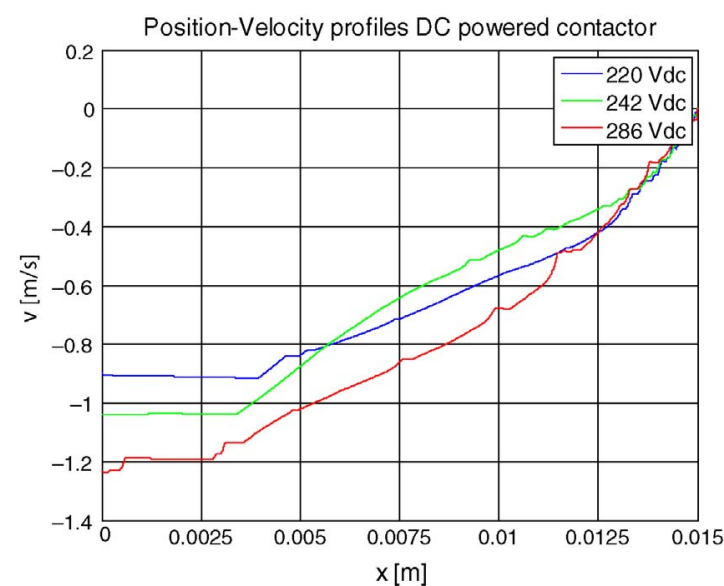

Fig. 15. DC powered profile position-velocity during the closure.

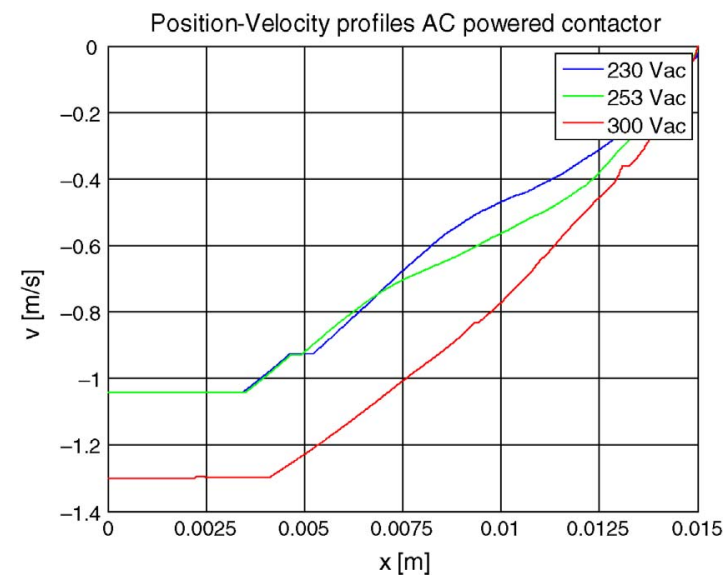

Fig. 16. AC powered profile position-velocity during the closure.

that appears when the current is flowing through the contacts. Therefore, the maximum current flows in the contactor coil. After this period $(100 \mathrm{~ms})$ the control circuit reduces the current coil ten times. This procedure saves energy and avoids overheating, which can destroy the coil.

\section{EXPERIMENTAL SETUP}

This paper has been applied to the contactor manufactured by GE Systems type CK10CE411 whose characteristics are: Contact rating: 400-V, 50/60 Hz, 408 A with AC3 category, $0.5 \times 10^{6}$ ops., $220 \mathrm{~kW}$. The path of the armature is $15 \mathrm{~mm}$ and the contact gap is $12.5 \mathrm{~mm}$.

Fig. 14 shows the utilized experimental setup. To validate the system, it is necessary to measure the velocity and the travel of the armature. A laser Doppler vibrometer Polytec OFV-3000/OFV-502 was used for this purpose. The system consists of an electronic controller and a non-contact standardoptic sensor head. It measures the acceleration and from it, by means of consecutive integrations, the velocity and position are obtained. Therefore, due to its own principle of operation there is no contact with the moving pieces of the contactor.

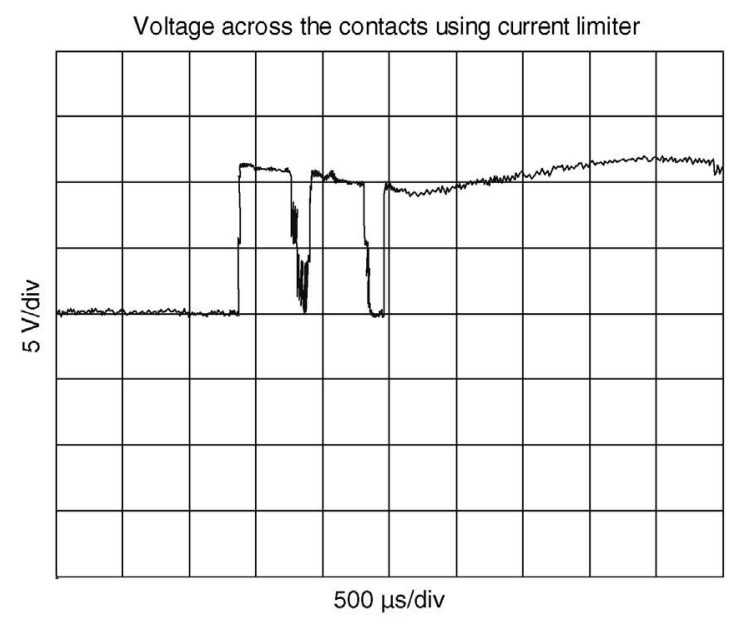

(a)

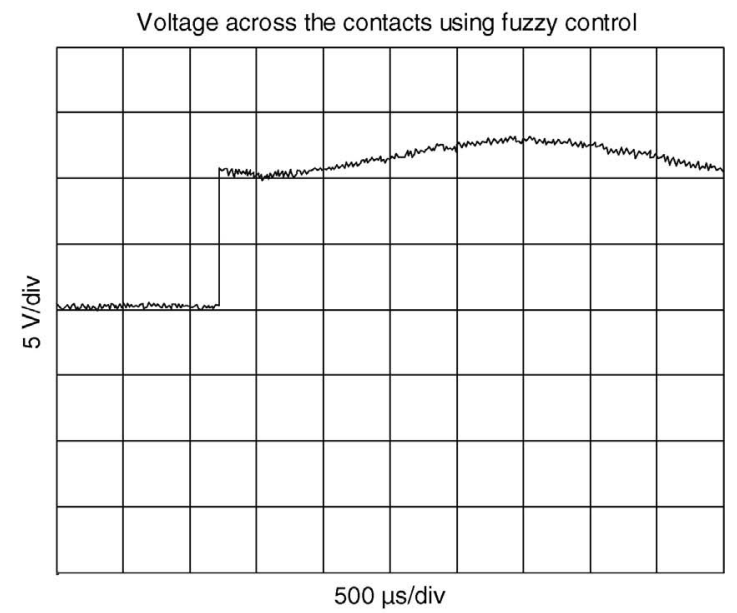

(b)

Fig. 17. (a) Voltage across the resistance terminals during the closure of the contacts being the contactor powered by the current limiter. (b) Voltage across the resistance terminals during the closure of the contacts when the contactor is fed by the developed control.

\section{RESULTS AND TESTING}

In order to validate the developed module several tests have been performed. They are illustrated in Figs. 15 and 16 as follows.

Fig. 15 shows the experimental profile of the armature velocity versus its position. It was acquired when the contactor was $220-\mathrm{V}, 242-\mathrm{V}$, and $286-\mathrm{V}$ dc powered. The closing action of the magnetic circuit begins at $x=15 \mathrm{~mm}$, and finishes at $x=0 \mathrm{~mm}$, where the moving armature reaches the fixed core. Fig. 16 depicts the action when the contactor is $230-\mathrm{V}, 253-\mathrm{V}$, and $300-\mathrm{V}$ and $50-\mathrm{Hz}$ ac powered. In all cases, as the contacts approach closure, the velocity of the armature increases to approximately $1 \mathrm{~m} / \mathrm{s}$ just before making contact, in the case that they were new.

As contacts wear, the pathway until they close is longer. Since the velocity before impact is fixed by the fuzzy controller to $1 \mathrm{~m} / \mathrm{s}$, the impact velocity remains the same as in the case when the contacts were new. This ensures that contact bouncing can be successfully eliminated in both new state and worn state contacts. 
In order to demonstrate that the developed control reaches these goals, as regards to the suppression of contact bounces, the following result is shown. A purely resistive load is switched on to a $10-\mathrm{V}$ dc power supply by means of the contacts of the contactor. Fig. 17 shows the voltage across the contacts with the developed electronic module and with the current limiter that is attached to the contactor.

\section{CONCLUSION}

The work presented here provides a controller for an electrical contactor that regulates the current through its excitation coil. Implementing this procedure ensures the closing speed of the armature is kept within predetermined limits before the closure, thereby eliminating contact bounce. As a result, in the event that the contactor is connected to a powered load, there will be far less contact erosion.

Comparing Figs. 15-17, it can be seen that the developed electronic module improves substantially the closing dynamics of the contactor, thereby suppressing the mechanical bouncing of the contacts. When the contactor is loaded, and as a result of the control strategy proposed in this paper, the contact bouncing is eliminated. Thus, the electrical arcs between the contacts are also eliminated. This, in turn, prolongs the life of the contactor.

Given that the control is a closed-loop type, and based on a fuzzy logic structure, the result is a control scheme that is selfadjusting to changing conditions, such as mechanical wear of the components and power supply conditions.

In this sense, future work will be carried out where the contactor will be subject to different external fed disturbances, such as voltage sags, short circuit events, and different faults in the coil, such as open turns and shorted turns, in order to study how the control acts under these circumstances.

\section{APPENDIX}

This paper has been applied to the contactor manufactured by GE Systems typed CK10CE411 rated for the following duty:

1) contact rating: $400-\mathrm{V}, 50 / 60 \mathrm{~Hz}, 408 \mathrm{~A}$ with $\mathrm{AC} 3$ category, $\left(0.5 \times 10^{6}\right.$ ops. $), 220 \mathrm{~kW}$;

2) coil rating: $660 \mathrm{VA}$;

3) armature closing time: $60 \mathrm{~ms}$.

And with the following physical operating characteristics:

4) path of the armature: $15 \mathrm{~mm}$;

5) contact gap: $12.5 \mathrm{~mm}$.

\section{REFERENCES}

[1] J. McBride and S. Sharkh, "Electrical contact phenomena during impact, electrical contacts," in Proc. 37th IEEE Holm Conf., 1991, pp. 132-140.

[2] T. J. Schoepf and F. Hauner, "Effects of different loads on the surface of silver metal oxide contacts for general-purpose relays," IEEE Trans. Compon. Packag. Technol., vol. 28, no. 4, pp. 728-733, Dec. 2005.

[3] M. Hasegawa, Y. Tamaki, and Y. Kamada, "An experimental study on minimum arc current for arcs longer than a few microseconds in relay contacts and possible reinterpretation of the meaning thereof," IEEE Trans. Compon. Packag. Technol., vol. 32, no. 1, pp. 127-134, Mar. 2009.
[4] J. Swingler and J. W. McBride, "Micro-arcing and arc erosion minimization using a dc hybrid switching device," IEEE Trans. Compon. Packag. Technol, vol. 31, no. 2, pp. 425-430, Jun. 2008.

[5] J. W. McBride, "An experimental investigation of contact bounce in medium duty contacts," IEEE Trans. Compon. Hybrids Manuf. Technol., vol. 14, no. 2, pp. 319-326, Jun. 1991.

[6] A. G. Espinosa, J. R. Riba, J. Cusidó, J. A. Ortega, and L. Romeral, "Contact bounce elimination by means of a sensorless closed-loop current controller in dc core contactors," in Proc. 54th IEEE Holm Conf. Electr. Contacts, 2008, pp. 117-124.

[7] P. Barkan, "A study of the contact bounce phenomenon," IEEE Trans. Power Apparatus Syst., vol. PAS-86, no. 2, pp. 231-240, Feb. 1967.

[8] D. Spath, V. Behrens, M. Finkbeiner, and O. Lutz, "The influence of the bonding area of welded contact tips on contact erosion," in Proc. 52nd IEEE Holm Conf. Electr. Contacts, 2006, pp. 181-187.

[9] X. Zhou and M. Little, "A novel concept for fault current tolerable contactors," IEEE Trans. Compon. Packag. Technol., vol. 28, no. 4, pp. 710-716, Dec. 2005.

[10] X. Zhou, L. Zou, and E. Hetzmannseder, "Asynchronous modular contactor for intelligent motor control applications," in Proc. 51st IEEE Holm Conf. Electr. Contacts, 2005, pp. 55-62.

[11] Y. Kawakami, M. Hasegawa, Y. Watanabe, and K. Sawa, "An investigation for the method of lifetime prediction of $\mathrm{Ag}-\mathrm{Ni}$ contacts for electromagnetic contactor," in Proc. 51st IEEE Holm Conf. Electr. Contacts, 2005, pp. 151-155.

[12] W. Li, J. Lu, H. Guo, W. Li, and X. Su, "AC contactor making speed measuring and theoretical analysis," in Proc. 50th IEEE Holm Conf. Electr. Contacts 22nd Int. Conf. Electr. Contacts, Sep. 2004, pp. 403407.

[13] S. Wang, W. Ren, and W. Fan, "Simulation of spring system's operation process for electromagnetic relay," in Proc. 50th IEEE Holm Conf. Electr. Contacts 22nd Int. Conf. Electr. Contacts, Sep. 2004, pp. 453458.

[14] J. R. Riba Ruiz and A. Garcia Espinosa, "A novel parametric model for ac contactors," IEEE Trans. Magn., vol. 44, no. 9, pp. 2215-2218, Sep. 2008.

[15] T. S. Davies, H. Nouri, and F. W. Britton, "Toward the control of contact bounce," IEEE Trans. Compon. Packag. Manuf. Technol. Part A, vol. 19, no. 3, pp. 353-359, Sep. 1996.

[16] R. A. Hurley and B. R. Quayle, "Electrical contactor with controlled closure characteristic," U.S. Patent 5128 825, Jul. 7, 1992.

[17] Y. Liu, D. Chen, L. Ji, and Y. Geng, "Dynamic characteristic and contact bounce analysis for an ac contactor with PWM controlled coil," in Proc. 53rd IEEE Holm Conf. Electr. Contacts, 2007, pp. 289-293.

[18] S. A. Hall, "Pulsewidth-modulating control of a nonlinear electromagnetic contactor," IEEE Trans. Ind. Elect., vol. 37, no. 3, pp. 241-249, Jun. 1990.

[19] C. T. Chi, "A study of closing adaptative control in electronically controlled intelligent contactor," in Proc. IEEE Region 10 Conf. (TENCON), Nov. 2006, pp. 1-4.

[20] T. Rosche, "Electronic control electromagnetic contactors," in Proc. 19th Int. Conf. Electr. Contacts, 1998, pp. 295-299.

[21] N. Mitlmeier, B. Streich, and D. Runggaldier, "Electromagnetic switchgear comprising a controlled drive, a corresponding method and a circuit," Property of Siemens EP1234316, Aug. 28, 2002.

[22] P. M. dos Santos Dias de Moraes and A. J. Perin, "An electronic control unit for reducing contact bounce in electromagnetic contactors," IEEE Trans. Ind. Electr, vol. 55, no. 2, pp. 861-870, Feb. 2008.

[23] A. G. Espinosa, J.-R.R. Ruiz, and X. A. Morera, "A sensorless method for controlling the closure of a contactor," IEEE Trans. Magn., vol. 43, no. 10, pp. 3896-3903, Oct. 2007.

[24] A. G. Espinosa, J.-R.R. Ruiz, J. Cusido, and X. A. Morera, "Sensorless control and fault diagnosis of electromechanical contactors," IEEE Trans. Ind. Electron., vol. 55, no. 10, pp. 3742-3750, Oct. 2008.

[25] J.-R. Riba Ruiz and A. Garcia Espinosa, "Design of an estimator of the kinematics of ac contactors," Eur. Trans. Electr. Power, vol. 19, no. 7, pp. 933-948, 2009.

[26] S. Jorgens, "A quantitative comparison of contactor characteristics for electronic controlled and conventional drives," in Proc. 20th Int. Conf. Electr. Contact, Sweden, 2000, pp. 1-6.

[27] B. Carse, N. Larsen, H. Nouri, and T. Davies, "An approach to the reduction of contact bounce using fuzzy control," in Proc. IEEE Int. Symp. Ind. Electron., vol. 3. 1999, pp. 1025-1029. 


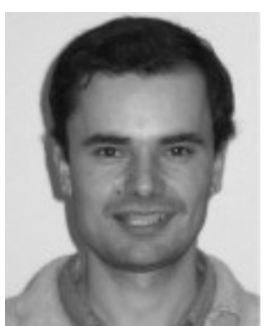

A. G. Espinosa (M'05) received the Electrical Engineering and the Ph.D. degrees from the Polytechnic University of Catalonia, Barcelona, Spain, in 2000 and 2005, respectively.

$\mathrm{He}$ is currently with the Motion and Industrial Control Group, Technical University of Catalonia, Terrassa, Catalonia, Spain. The Group's major research activities concern induction and permanent magnet motor drives, enhanced efficiency drives, and fault detection and diagnosis of electrical motor drives. His current research interests include electromagnetic devices, electric machines, variable-speed drive systems, and fault detection algorithms.

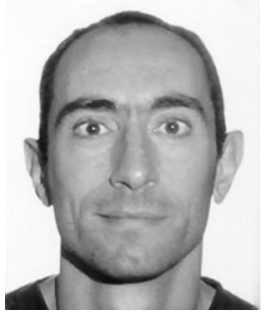

J. R. R. Ruiz received the M.S. degree in physics and the Ph.D. degree from the University of Barcelona, Barcelona, Spain, in 1990 and 2000, respectively.

In 1992, he was a Full Time Lecturer with the College of Industrial Engineering of Igualada, Igualada. Spain. He is currently with the Motion and Industrial Control Group, Technical University of Catalonia, Terrassa, Catalonia, Spain. The Group's major research activities concern induction and permanent magnet motor drives, enhanced efficiency drives, and fault detection and diagnosis of electrical motor drives. His current research interests include electromagnetic shields, electromagnetic actuators, and electrical drives.

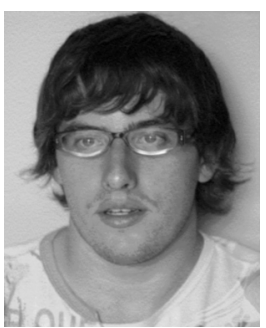

J. Cusidó (M’05) received the Electrical Engineering degree from the Polytechnic University of Catalonia (UPC), Barcelona, Spain, in 2005.

In 2005, he joined the Electronic Engineering Department, UPC, where he is currently an Assistant Professor. $\mathrm{He}$ is with the Motion and Industrial Control Group, Technical University of Catalonia, Terrassa, Catalonia, Spain. The Group's major research activities concern the motor fault detection algorithms, automotive drive applications, data acquisition systems and signal processing, and adaptive control.

Mr. Cusidó is currently a Member of the Technological Center of Manresa, where he is the responsible person for technological assistance to several industries and university departments in fields of automotive and aeronautical applications.

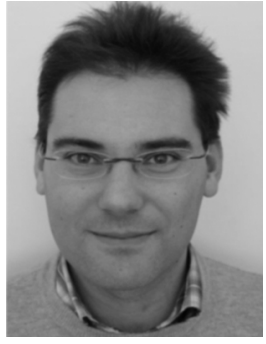

remote labs.
Juan A. Ortega received the M.S. Telecommunication Engineer and Ph.D. degrees in electronics from the Polytechnic University of Catalonia (UPC), Barcelona, Spain, in 1994 and 1997, respectively.

In 1994, he joined the UPC Department of Electronic Engineering, as a Full Time Associate Lecturer. He is currently with the Motion and Industrial Control Group, Technical University of Catalonia, Terrassa, Catalonia, Spain. His current research and development areas include motor diagnosis, signal acquisition, smart sensors, embedded systems, and

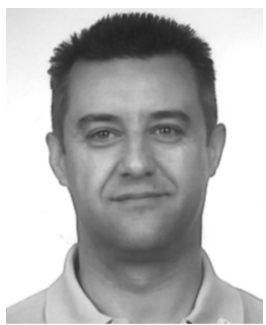

L. Romeral (M'98) received the Electrical Engineering and the $\mathrm{Ph} . \mathrm{D}$. degrees from the Polytechnic University of Catalonia (UPC), Barcelona, Spain, in 1985 and 1995 , respectively.

In 1988, he joined the Electronic Engineering Department of the UPC, where he is currently an Associate Professor. He is with the Motion and Industrial Control Group, Technical University of Catalonia, Terrassa, Catalonia, Spain. His current research interests include electric machines, power electronics converters and modulation strategies, variable-speed drive systems, fault detection and motor diagnosis, and microprocessor-based real-time control algorithms. 